\title{
Think Tanks and Good Governance: The Case of the Korea Development Institute (KDI)
}

\author{
JONGRYN MO* AND JEONG YEON LEE**
}

This paper introduces a set of analytical frameworks for explaining the configuration and performance of different policy research systems. Building upon these frameworks, we identify three major contributing factors to the creation of an efficient policy research system in Korea while paying particular attention to the Korea Development Institute (KDI). Those factors include: (i) a favorable policy environment; (ii) an optimal organizational arrangement; and (iii) effective incentive and discipline mechanisms. Among possible lessons from the KDI model that can have important bearings on other countries, we emphasize the importance of institutional and individual incentives. But incentive systems would not have worked without the KDI's open and "liberal" organizational culture. Non-economic factors such as the recognition as a center of excellence have also been as important to KDI success as financial rewards. It is also important to recognize that these success factors, strong incentives, organizational culture and non-financial recognitions, do not work independently; rather, they reinforce one another.

Keywords: Public Policy, Think Tanks, Governance, KDI, The Developmental State

* Professor, Yonsei University, Seoul, South Korea; E-mail: jrmo@yonsei.ac.kr

** Corresponding author, Associate professor, Yonsei University, Seoul, South Korea; E-mail: leejy@yonsei.ac.kr;

DOI: 10.16934/isr.15.2.201412.93 


\section{INTRODUCTION}

The quality of policy research was one of the key ingredients of the Korean economic model. In explaining Korea's economic performance, scholars have explored the nature of institutional arrangements that enabled political leaders to choose and implement efficient public policies. Since Chalmers Johnson first named the collection of those institutions "the developmental state," many have sought to understand the origins and mechanics of the developmental state (Amsden 1990; Wade 1990; Onis 1991; Moon and Prasard 1994; Haggard and Mo 2000). In discussing the East Asian developmental state, three distinctive institutional features have been observed: business-government cooperation, bureaucratic autonomy and capacity, and authoritarian rule.

Under these institutions, Korean political leaders were privileged with quality policy advice from their bureaucrats. The central player in the Korean economic bureaucracy was the Economic Planning Board (EPB) that used its planning, budget, and foreign exchange allocation power to formulate and implement a series of five-year economic plans since the early 1960s. The literature on Korean political economy is filled with the stories of Korean bureaucrats in the pilot agencies like the EPB (Amsden 1990; Clifford 1998). There are also academic efforts to study the success of the EPB from an organizational theory perspective (Han 2014).

What is missing in the literature, however, is a serious look into the role of public policy think tanks in policy development and implementation. The EPB bureaucrats, after all, relied on government think tanks for the policy research that they needed to formulate effective policies (Shinohara et al. 1983; World Bank 1983, 68). But this simple story begs the question of what the government actually did to design and manage an effective policy research system in Korea. Answering this question involves more than a historical narrative; we must analyze the Korean model from a general theoretical perspective. Unless we study the Korean case in the theoretical context, it is not possible to understand what was unique about the Korean experience and more importantly, what made it successful.

Although there are several analytical frameworks already on offer for evaluating think tanks, they tend to focus mainly on ranking the existing think tanks. In this study, we introduce a set of theoretical frameworks that extend beyond simply ranking the existing think tanks and explain the configuration and performance of different policy research systems. Subsequently, the analysis of the Korean experience based on our frameworks provides important lessons for developing country governments that seek to establish policy research systems of their own as successful as the one in Korea.

In telling the Korean story, the paper pays particular attention to the Korea Development Institute (KDI) that has maintained its position as the center of 
excellence since it was founded in 1971. The institution has also served as a model for think tanks in other developing countries. For example, Korea and Myanmar recently signed a memorandum of understanding on establishing a government think tank in Myanmar that will be modeled after the KDI. Building upon the KDI case, this paper shows how to govern a think tank as well as how to design an effective governance system around think tanks.

\section{EVALUATION OF THINK TANKS: THE EXISTING FRAMEWORKS}

Clark and Roodman (2013) reckon that the existing frameworks for evaluating think tanks broadly take three different approaches. The first of these is based on the quantitative assessment of policy impact (Ruble 2000; Posen 2002; Trimbath 2005). In these studies, the number of citations in traditional mass media typically serves as a main quantitative measure of policy impact. Since the number of citations is readily available data, the quantitative measure based on citations is relatively easy to construct as well as to update. Subsequently, one can make reasonable cross-sectional and time-series comparisons of policy impact using this approach. Clark and Roodman (2013) include not only news media citations but also web traffic and social network followers in their framework, given the everincreasing role of non-traditional media in public discourse.

The second approach adopts a qualitative assessment instead of a quantitative assessment. For example, Prospect Magazine (2012) assembles an expert panel that conducts in-depth reviews of a small sample of think tanks and identifies those that have made significant policy impact. Although the panel's reviews are subjective, they recognize the best practices in light of the well-established achievements by relying on specific and detailed award citations. This second approach has clear advantages and limitations in comparison with the first approach. A qualitative assessment is able to provide a much more multifaceted and nuanced picture than a quantitative measure that solely depends on media citations. Relative to the first approach, however, the second approach is likely to be more limited in its coverage of think tanks and also its frequency because a qualitative assessment tends to be more costly in terms of time and labor than a quantitative assessment.

Finally, the best known effort to evaluate think tanks, the Global Go To Think Tank (GGTTT) rankings published by the Think Tanks and Civil Societies Program (TTCSP) at the University of Pennsylvania, involves a perception-based assessment. Their annual rankings of think tanks around the world are based on the perceptions of peers and experts. McGann (2014) provides the latest rankings for 2013, covering more than 6,000 institutions and involving over 9,000 peers and experts from the press, academia, donors and think tanks. The vast coverage and frequency clearly serve as advantages of these perceptions-based rankings. However, 
they are not without criticism. Criticism ranges from the ambiguous definition of the term think tank and the opaque identity of experts who rank them to tallying errors (Clark and Roodman 2013, 2). Furthermore, it is often argued that although the GGTTT rankings may be intended to induce think tanks to pursue good performance, the publication offers little meaningful information about what think tanks should do to improve their performance.

Therefore, all three approaches listed above show clear strengths as well as weaknesses in evaluating think tanks. However, none of them is particularly useful for guiding developing countries in their efforts to establish effective policy research systems of their own because all three approaches focus heavily on ranking existing institutions. In the next chapter, we try to fill this important gap by introducing a new set of analytical frameworks.

\section{ANALYTICAL FRAMEWORKS}

There are three basic analytical issues concerning the type and performance of a policy research system. First is how favorable the policy environment is for quality policy research in a given policy area; the idea is that unless environmental conditions change, there is a limit on what organizational reorganization and reform can do to improve the quality of a policy research system. The second issue is how to organize and configure a policy research system, given a specific policy environment. Key decisions to make include: (i) whether to set up one comprehensive think tank or have different organizations for different policy areas; and (ii) how to link research and training functions. No matter how unfavorable the environment may be, it is still worthwhile to design the best possible organizational arrangement. The third issue is what the government can do to make its government think tanks perform better. Economics provides useful frameworks for addressing each of the three issues.

\section{The market for Public Policy Research}

How would economists analyze the amount and quality of policy research in a given sector? They would consider research output as a good, policymakers as consumers, and think tanks as producers (Mo 2001). The key normative question for economists is then whether the existing level of policy research is socially optimal. In most developing countries, it is fair to say that policy research is undersupplied, i.e., produced at a level lower than socially desirable. Causes of the undersupply lie both in the demand and supply sides.

On the demand side, policy may not be important to political leader and policymakers. The end users of policy research are politicians because they use them to make policy decisions. If policy outcomes are not important to politicians' 
interests, they do not have much demand for policy research. For example, if policy is not an important determinant of electoral outcome in a democracy, politicians whose main interest is winning elections would not seek policy advice or research. Unfortunately, this is precisely the situation in many underdeveloped countries. Therefore, in analyzing the environment for good policy research in any given sector, it is important to evaluate the degree to which political leaders (and policymakers) are held accountable for their policy performance.

The demand for policy research by political leaders also depends on the degree to which they favor the policy-based rather than the politics-based style of governance. A variation in policy responsiveness can be found even among authoritarian leaders. Historically, we can identify many authoritarian leaders who can be called "policy wonks" in today's jargon. Lee Kwan Yew and Park Chung Hee are some of the more prominent examples.

Another problem on the demand side is that political power, i.e., the authority to make policies, is so concentrated among a few political leaders that the number of people who need policy research is small. Compare federal with non-federal systems, for example. The number of political leaders with demand for policy research would be much higher under a federal system than under a non-federal system simply because the former gives more people more real authority than the latter.

It is wrong to assume that only government think tanks are the producers of policy-relevant research. Traditionally, it is the bureaucrats who are the main sources of policy advice for political leaders. To the extent that good policy advice requires good policy research, it is inevitable that a large part of bureaucratic work involves some type of research. There are also other non-governmental sources of policy research. For example, aid agencies, international organizations, universities, private sector think tanks, and research-oriented NGOs are important producers of policy research. Therefore, in designing a policy research system, political leaders need to decide what types of research government think tanks will conduct and what types they will outsource or rely on from bureaucrats and non-governmental organizations.

Nevertheless, government think tanks, which are the focus of our analysis, are expected to be the main producers of policy research. As suppliers of policy research, think tanks are influenced by supply-side variables, i.e., the cost of inputs as well as the efficiency with which they are used. Inputs for policy research such as funds and researchers are scarce and expensive in most developing countries.

Because of weak government finances and private sector under-development, it is difficult for think tanks to raise funds in almost all Third World countries. Neither do most developing countries give tax incentives for charity and donations. A rigid labor market is another barrier to attracting qualified researchers to think tanks. In most developing economies, the labor market is segmented, so once 
researchers start working for a think tank, they cannot expect to move to other jobs later.

Skills involved in managing think tanks may be another constraint on the production of quality research. Management know-how may be especially lacking in new democracies or transition economies.

Another supply-side problem in developing economies may be access to information. In developing countries, government think tanks often dominate because of their access to the information held by bureaucrats. To encourage the development of private-sector think tanks, it is important to introduce legislation such as Freedom of Information Act in the United States or Information Disclosure Law in Korea, which allows individual citizens and NGOs to request data and information from government agencies.

The market analogy for a policy research system presents a useful framework for understanding the basic incentive structure of the system. But a policy research system cannot be organized as a market. There would be simply too many market failures in a market for policy research. First, there are certain scale economies for policy research production, making small developing countries incapable of supporting a large number of think tanks. Second, policy research is largely a public and not a private good. That is, once policy research is produced, there is no way of preventing others, consumers or producers, from gaining access to it. Thus, private-sector think tanks have little incentive to produce at a socially optimal level because they cannot capture all the subsequent social benefits. In many developing countries, the weak protection of intellectual property thus works to discourage the development of new ideas because inventors are not properly credited or compensated.

\section{Organization and Design of Policy Research Systems}

Because the market alone is not capable of producing necessary policy research, it is almost always the government's job to design and organize a policy research system in a given policy area.

Areas of policy research should be defined functionally. For example, economic policy, social policy, science and technology policy, and foreign policy constitute the broadest categories of policy research. In each policy area, there are subareas of research. In economics, for example, typical sub-areas are labor, public finance, international trade and finance, welfare, and banking. In thinking about a policy research system in the realm of economic policy, policymakers must decide how to organize think tanks along the sub-areas of research.

We now turn to economics again for useful concepts that we can apply to this "industry-level" problem. The first important concept is scale economies. "Economies of scale exist when the production cost of a single product decreases with the 
number of units produced; economies of scope are cost-saving externalities between product lines" (Tirole 1988).

If policymakers want to take advantage of economies of scale in the production of policy research, they should not assign more than one think tank to each sub-area. An interesting question becomes how to bundle sub-areas to exploit possible economies of scope. Some of the natural combinations are taxation and budgeting, international trade and finance, and banking and macroeconomic policy. There are also some new combinations that are becoming popular; in Korea, for example, education and national human resources management are considered desirable pairs with synergic effects, on the basis of which the government created and operated the Ministry of Education and Human Resources Development from 2001 to 2008.

One research sub-area of any research area is synthesis and coordination, and this synthesizing function should be performed by either an existing sub-area think tank or a separate synthesizing think tank. The KDI can be understood as such a synthesizing think tank, meeting the demands of multiple ministries in multiple sub-areas.

Another important concept is competition. Even where there are scale economies in the production of policy research, economics tells us that it is desirable to have more than one think tank in any given area of policy research.

One way to ensure some level of competition in a given policy area is to establish one comprehensive think tank so that it can be relied on as an alternative source of policy advice on the output produced by sub-area think tanks. This comprehensive think tank can also act as a center of excellence to which most important area-wide research projects are assigned. Since this model features one comprehensive think tank plus one think tank in each sub-area, it can be called the " $1+\mathrm{N}$ " model. Alternative models are the unitary model, where all policy research in a given area is centralized under one organization, and the $\mathrm{N} \times \mathrm{N}$ model, where there are multiple think tanks in every sub-area.

Often, boundaries of policy research follow those of bureaucratic jurisdiction, not objective functional criteria. But the principles are the same even if political leaders try to organize think tanks along jurisdictional lines. They still have to decide how many think tanks to assign to each ministry and whether to create a comprehensive think tank covering several ministry jurisdictions.

\section{Mechanisms of Incentives and Discipline}

Because of institutional inertia and bureaucratic politics, it is often difficult to abolish or merge existing organizations. Thus, to improve the performance of think tanks, political leaders will have to rely on incentive arrangements instead of "industry-level" reorganization. That is, how can existing organizations be made 
work better? Here, agency theory can provide useful insight. Agency theory emphasizes the importance of external and internal discipline in aligning the incentives of agents (which are government think tanks in this case).

In a market, the market decides upon the winners and losers. What is efficient about the market is that the losers are forced to leave the market. With government think tanks with little competition from the market, the only external source of competition and thus, discipline may come from other government think tanks. Thus, it is important that there is more than one organization with expertise in a particular policy area.

The government (or political leaders) can also exert discipline through more direct measures. The government can choose from many different supervisory arrangements. It can put government think tanks under the control of minister, vice-minister, independent commission or even the head-of-state. It can also decide whether to subject a think tank to review by one or multiple supervisory organizations.

The government can also tie institutional performance to the budget and individual salaries. To provide strong incentives, the government can give marketrate salaries to researchers. Some governments have gone further by offering salaries higher than the prevailing market rates.

The government should also decide how much autonomy to give to its think tanks. The key issue here is academic freedom. The long-term success of a think tank depends on the quality of its research, and it is not possible to attain it without meeting internationally recognized professional standards. Equally important to professional integrity is internal organization culture. A think tank cannot properly function without open communication and debate among its members.

\section{THE KOREAN EXPERIENCE}

\section{The Evolution of the Korean Public Policy Research System}

The bureaucracy has always been the main source of policy advice in Korea. But its role has been transformed through several stages. In each stage, new policy research organizations emerged to support or compete with bureaucratic agencies in policy research. During the 1960 s, the bureaucrats dominated domestic policy advice. Their only competitors were external aid agencies.

\section{(1) Ministerial Think Tanks (1971-)}

In the early 1970 s, industrialization accelerated. Korea was moving into heavy and chemical industries after successfully developing light manufacturing Industries throughout the previous decade. Reflecting the changing industrial structure, there was a change in the nature of the policy advice demanded. At the working 
level, too, there was a growing recognition that economic planning should be based on the comprehensive and in-depth empirical research to promote the longterm public interest. As early as 1966, the need for a think tank was raised among policymakers when they were preparing the $2^{\text {nd }}$ Five-Year Economic Plan (19671971).

In response to the demand for think tanks, the government established the Korea Development Institute in 1971 as a semi-official think tank under the Economic Planning Board. The funds came both from the United States and the Korean government. USAID allowed the Korean government to divert 1.3 billion won from the foreign aid account to the KDI endowment fund and provided additional 1.3 million dollars to support various KDI programs. The financial contributions by the Korean government amounted to 500 million won.

At first, the KDI was the government's only economic policy think tank. Over time, however, the scope of KDI research decreased as other government agencies created their own think tanks, taking relevant research departments away from the KDI. In terms of policy coverage, it can be said that the original KDI has been divided into multiple independent think tanks. This process began in 1976 when the Ministry of Trade and Industry created the Korea Institute for International Economics, which later became the Korea Institute for Industrial Economics and Trade (KIET), followed by the creation of the Korea Rural Economic Institute by the Ministry of Agriculture and the establishment of the Korea Research Institute for Human Settlement by the Ministry of Construction in 1978.

Bureaucratic politics was one factor in the subsequent growth of ministerial think tanks. But changing research demands also played a role. As the Park government began the Heavy and Chemical Industry Drive in the mid-1970s, the demand grew for industry-level analysis and research, prompting the establishment of the KIET.

By the early 1990s, concerns grew over the number of ministerial think tanks; by then, it became common that each ministry was supported by multiple think tanks. According to our typology, the Korean policy research system rapidly moved from the 1 model to the $1 \times \mathrm{N}$ model and was moving in the direction of the $\mathrm{N} * \mathrm{~N}$ model.

The proliferation of ministerial think tanks became subject to public criticism. First, there were jurisdictional overlaps. Although the overlaps can, in theory, be a means to increase the supply of alternative policy ideas, in Korea they reflect the bureaucratic desire to expand jurisdiction and secure resources rather than to offer new policy ideas. Second, they were used to support government intervention in the economy. Third, ministerial think tanks were criticized for being inefficient.

In 1998, the Kim Dae Jung government made a serious effort to reform the policy research system. Among the alternatives proposed at the time were the return to the 1 model, the merging of ministerial think tanks along functional areas, 
and the consolidation of think tanks within the ministry. In the end, the status quo prevailed in terms of the number of think tanks. Supporters of the status quo argued that it was important to make alternative views available to policymakers and more than one think tank in a given policy area was necessary to generate alternatives; because of the Korean organizational culture, which tends to be dominated by the top leader, it would be unrealistic for one think tank to present alternative options to policymakers. Instead, the government decided to change the governance structure of ministerial think tanks. Instead of having a separate board for each think tank, which had been the practice at the time, the government created a single board, called the National Research Council for Economics, Humanities and Social Sciences (NRCS), to supervise all ministerial think tanks in the areas of economic and social policy.

\section{(2) Private Sector Think Tanks (1981-)}

The year 1979 marked a watershed in Korean history. President Park Chung Hee was assassinated in October of 1979. It was also the year when the government began to stabilize the economy after realizing the costs of the Heavy and Chemical Industry Drive. The new Chun Doo Whan government embraced this change of policy and made economic stabilization and liberalization its top priority. As the government began to rethink its role in the economy, the private sector saw an opportunity to have its own input into policy. In 1981, the Federation of Korean Industries, a main lobbying group for business, created the Korea Economic Research Institute (KERI) as an alternative source of policy advice to promote business interests and perspectives. Individual chaebol groups followed suit by setting up their own in-house economic think tanks, Daewoo in 1984, and Samsung and LG in 1986.

Although not fully private in nature because of their vulnerability to government influence, think tanks affiliated with industry associations, especially in the financial sector, also arose around this time. Industry associations, such as the Korea Association of Commercial Banks who established the Korea Institute of Finance, thus became active in the market for policy ideas.

\section{(3) Movement and Civil Society Groups (1985-)}

Trends in civil society since the mid-1980s provide another factor for observation. In the mid-1980s, Korea witnessed a strong pro-democracy movement, led by unions, churches, students and dissidents. After Korea made the transition to democracy in 1987, a large number of pro-democracy groups and activists turned their attention to civil society issues such as the environment, anti-corruption, political reform and economic justice. The Citizens' Coalition for Economic Justice 
and the People's Solidarity for Participatory Democracy have been the most successful in pushing reform agendas to the fore. It is fair to say that though bureaucrats and their think tanks continue to dominate policy advice, there have been serious challenges from NGOs and private sector think tanks since the transition to democracy began in the 1980s.

Table 1. The Evolution of the Korean Public Policy Research System

\begin{tabular}{|c|c|c|c|}
\hline & $\begin{array}{c}\text { Developmental State } \\
(1971-)\end{array}$ & $\begin{array}{c}\text { Democratizing } \\
(1987-1996)\end{array}$ & $\begin{array}{c}\text { Democracy } \\
(1996-)\end{array}$ \\
\hline Leadership priorities & Economic growth & $\begin{array}{l}\text { Economic growth } \\
\text { Social welfare }\end{array}$ & $\begin{array}{l}\text { Economic growth } \\
\text { Economic justice } \\
\text { Balanced development }\end{array}$ \\
\hline $\begin{array}{l}\text { Place(s) of policy } \\
\text { initiative }\end{array}$ & - Ministries & $\begin{array}{l}\text { - Ministries } \\
\text { - Presidential } \\
\text { commissions }\end{array}$ & $\begin{array}{l}\text { - Ministries } \\
\text { - Presidential commissions }\end{array}$ \\
\hline $\begin{array}{l}\text { Main producer of } \\
\text { research }\end{array}$ & $\begin{array}{l}\text { The comprehensive } \\
\text { think tank (KDI) }\end{array}$ & Ministerial think tanks & Ministerial think tanks \\
\hline Competing providers & Few & $\begin{array}{l}\text { Chaebol think tanks } \\
\text { NGOs }\end{array}$ & $\begin{array}{l}\text { Chaebol think tanks } \\
\text { NGOs } \\
\text { Ideology-based think tanks }\end{array}$ \\
\hline
\end{tabular}

\section{An analysis of the KDI model}

\section{(1) Policy Environment, Organizational Arrangement and Incentive Mechanisms}

The leading actor in the Korean story remains the Korea Development Institute. The turning point in the development of the policy research system in Korea was the creation of the Korea Development Institute in 1971, which has not lost its position as the premier economic think tank in Korea. It has also won international recognition; the Economist, for example, rated KDI as one of the most influential think tanks in the world in 1986. If the Korea Development Institute or the policy research system built around it was a success, it begs the question of why. The theoretical frameworks developed in Chapter III give us a few clues.

One possibility is that environmental factors for successful government think tanks were favorable in 1971. The first positive factor was the availability of quality researchers; because of social emphasis on education, many students had gone abroad to pursue advanced degrees and by 1971, there were enough foreigntrained economists working abroad that the government could recruit. Also present was a strong and capable bureaucracy; without capable bureaucrats, who use policy research to provide policy advice, good policy research cannot be turned into good policy decisions.

Demand conditions were also favorable. President Park put economic growth 
on the top of his agenda; poverty eradication was the number one of his 10-point public pledge after leading a successful coup in 1961. Economic growth was to substitute for the weak democratic legitimacy of his regime as well as to increase the legitimacy of South Korea vis-à-vis the communist North. According to this view, potential threats to his regime, both internal and external, motivated President Park to pursue economic growth.

President Park's governing style facilitated the development of think tanks. Perhaps because he was familiar with the Japanese experience, he thought it necessary to build strong economic planning machinery and created a pilot agency called the Economic Planning Board in 1961. The KDI came naturally as a part of his effort to strengthen the EPB in the early 1970s. His intellectual approach to policy-making should be noted; he took economic issues seriously and actively participated in policy debate with his advisors.

Relatively little is known about why the Park Chung Hee government decided to establish a centralized and comprehensive think tank instead of multiple subarea think tanks. One reason was clearly a budget constraint; most of the initial KDI funds came from the United States and it was probably impossible to secure additional funds even if the Park regime desired another think tank. The fact that drafting five-year economic plans was the most important policy task at the time strengthened the case for a comprehensive think tank.

The success of the KDI can also be attributed to its unique incentive system. KDI, which began with a large endowment, has always received large funding from the government. At the individual level, too, the government gave special treatment to the KDI. In addition to above-the-market salaries, KDI fellows were provided with various perks such as chauffeur-driven cars, secretaries, personal research staff, and apartments.

The governance structure was also interesting. Officially, the EPB oversaw the KDI by appointing its president and approving its budget. But the relationship between the EPB and KDI was not one-sided; the KDI maintained a high level of autonomy. One reason was that the president himself took a personal interest in the management of the KDI, which enhanced KDI's prestige and helped KDI gain a degree of autonomy from the ministry.

Ultimately, it was the quality of research produced by the KDI that solidified its position as a center of excellence. In this regard, the leadership of the first president, Kim Man-Je, was instrumental. To maintain an open and democratic communication culture, he kept the size of the KDI deliberately small, minimized the internal bureaucracy, and insisted upon staying in the core competencies of comprehensive economic analysis. In the process, he had to clash with the government to fight government pressures to take over other government think tanks and take on more research areas. One indication of this focus on organizational coherence is that the KDI has always been reluctant to hire non-econo- 
mists even as the demands for social and political research mounted.

(2) Organizational Reform of 1999

TABLE 2. KDI: OLD AND NEW

\begin{tabular}{|c|c|c|c|}
\hline & & The Classical KDI Model & Post-1999 KDI \\
\hline \multicolumn{2}{|c|}{ Supervisory Structure } & Own board & $\begin{array}{l}\text { National Research Council for } \\
\text { Economics, Humanities and Social } \\
\text { Sciences (NRCS) }\end{array}$ \\
\hline \multirow{4}{*}{$\begin{array}{l}\text { Relationship } \\
\text { with } \\
\text { the Ministry }\end{array}$} & Budget & $100 \%$ direct support & $\begin{array}{l}\text { Exclusive contract } \\
\text { Open competition }\end{array}$ \\
\hline & $\begin{array}{l}\text { Research } \\
\text { Agenda }\end{array}$ & Close consultations & $\begin{array}{l}\text { Ministerial consultations } \\
\text { Board coordination } \\
\text { Open solicitation of research topics }\end{array}$ \\
\hline & Appointment & De facto ministry appointment & Public solicitation of applicants \\
\hline & $\begin{array}{c}\text { Report } \\
\text { Presentation }\end{array}$ & Coordination with the ministry & $\begin{array}{l}\text { Compliance with evaluation } \\
\text { guidelines }\end{array}$ \\
\hline \multicolumn{2}{|c|}{$\begin{array}{c}\text { Relative Compensation } \\
\text { Level }\end{array}$} & Extra-market & Market \\
\hline \multirow{2}{*}{$\begin{array}{c}\text { Mechanisms } \\
\text { of Incentives } \\
\text { and } \\
\text { Discipline }\end{array}$} & Institutional & Opportunities for promotion & $\begin{array}{l}\text { Project outsourcing (bidding) } \\
\text { Performance-based budget } \\
\text { allocation }\end{array}$ \\
\hline & Individual & $\begin{array}{l}\text { Promotion based on performance } \\
\text { Pay based on contract research }\end{array}$ & $\begin{array}{l}\text { Promotion based on performance } \\
\text { Pay based on contract research }\end{array}$ \\
\hline \multicolumn{2}{|c|}{ Communication culture } & Open & Open \\
\hline
\end{tabular}

The greatest organizational change in the KDI took place in 1999 when the government placed KDI, along with all other ministerial think tanks in economic and social policy areas, under the supervision of a unified board, the National Research Council for Economics, Humanities and Social Sciences. As a result, the relationship between the home ministries and the KDI radically changed.

Before the 1999 reform, the Ministry of Finance and Economy (MOFE), the successor to the Economic Planning Board, was the main ministry that the KDI served. As the home ministry, the MOFE had strong influence on the budget, agenda-setting, appointment and report presentation of the KDI. After 1999, however, their relationship became much more indirect. The Ministry of Strategy and Finance (MOSF), the successor to the MOFE, is now represented on the board of directors of the NRCS along with six other ministries and the Office for Government Policy Coordination, even though it still works closely with the KDI because most of the KDI work falls under its jurisdiction.

Under the new NRCS system, home ministries directly fund part of the research projects of their ministerial think tanks through exclusive contracts. Ministerial think tanks also pursue additional research projects in open compe- 
tition with other research institutes including university and private sector think tanks. Because ministerial think tanks are forced to compete under the new system, a predictable pattern has emerged with a disproportionate portion of "open bidding" funds going to strong think tanks.

The selection process involving research projects also changed. Although the KDI works closely with related ministries, other actors have become important sources of ideas. The NRCS, for example, has the formal authority to review and approve the KDI's research plans and does, in fact, ask the KDI to adjust its plans for various reasons. One of the NRCS's main concerns is to minimize the duplication of research among ministerial think tanks. In an effort to meet the demand of its consumers, i.e., academics, ministries, media and NGOs, the KDI sends letters to them, asking for their advice on future research projects.

Before the 1999 reform, the MOFE minister had the de factor power to appoint the president of the KDI. In the post-reform period, both the formal and actual appointing power has been transferred to the NRCS. When a position opens in a ministerial think tank, the NRCS advertises the job opening and solicits applicants. Although the influence of home ministries is still significant under the new system, it is much more indirect and limited than under the old system.

Compared with the past, the KDI now pays much more attention to the presentation and dissemination of research output. One reason is that the NRCS places strong emphasis on the impact and utilization of research output when it evaluates the performance of ministerial think tanks. NRCS evaluations are not a formality; they are an important determinant of entire think tank budgets as well as the salaries of think tank presidents. Another reason is that the KDI's constituents are no longer an exclusive club of bureaucrats and other policymakers. Under democracy, there are many social actors with a stake in KDI research, such as business, NGOs, and politicians, so the KDI needs to satisfy their demands.

The individual incentive structure did not change as much. The KDI has always evaluated its fellows on a systemic basis, and allowed fellows to be personally rewarded for winning outside contract research projects. KDI leaders are also aware that if top researchers are not properly rewarded, they would leave for other career opportunities in the government or academia; this "threat of exit" may have been as important to the success of the individual incentive system as the merit-based promotion policy. The difference now is that the KDI as an institution relies much more on contract research projects, so there are more opportunities for fellows to increase their individual income. Under the new deregulated market of contract research, the KDI has benefited considerably, raising the salaries of fellows above those of university academics. One area where the old tradition remains is organizational culture. KDI has always fostered an open and democratic organizational culture, and it remains largely intact.

As a result of the 1999 reform, the management of ministerial think tanks 
changed in important ways. As we have seen in the case of the KDI, ministerial think tanks have become more independent of their line ministries, faced more market pressure, and become more conscious of accountability to the general public. Nonetheless, the effects of the 1999 reform may have not been altogether positive. As outside research projects, many of which are funded by the private sector, are now more important as a source of revenue, the research priority of ministerial think tanks has also shifted toward management research away from policy research.

\section{(3) Emerging Challenges}

Since the early 1980 s, the KDI has been a champion of economic liberalization in the country. This direction has been palpable in their advice in many different fields, and been largely intact irrespective of the ideological leanings of the government in power. It was never a result of deliberate maneuvers from the top, but mainly reflects the mainstream economic training of most fellows in the KDI. Amsden (1994) coined the term, "American-trained Korean economists (ATKEs)," to suggest it as a major factor behind the country's policy direction that was clearly in support of economic liberalization. Kang (2012) argues that ATKEs have been instrumental in bringing on financial liberalization in the country. In fact, Korea's government think tanks, and the KDI in particular, are traditionally strongholds for A-TKEs. As of May 2010, more than three quarters of KDI fellows obtained their doctoral degrees from US universities (Kang 2012, Table 4).

Although economic liberalism dominated the global economic order for decades, its validity has been sharply thrown into doubt since global financial crisis erupted in 2007. Despite recent signs of economic recovery in many parts of the world, the suspicions targeted at economic liberalism still resonate well with the general public all over the world, including Korea. This has substantially transformed the political landscape in Korea, and hence posed fresh challenges to the policy environment of the KDI and other government think tanks whose traditional policy prescriptions tended to be rooted in economic liberalism.

The KDI is also facing different challenges as 36 government ministries and agencies have moved to Sejong City. The NRCS and 16 other research institutions including the KDI are now headquartered in their new locations in Sejong. Given a high concentration of population and economic activities in the Seoul metropolitan region and the resulting benefits Seoul offers in many respects, the relocation of research institutions to Sejong has prompted an exodus of fellows from those institutions for positions located in Seoul. According to the NRCS report to the National Assembly in October 2013, research institutions under their auspices lost 524 researchers, including 51 from the KDI, during 2009-2013. 
Despite such challenges, the relocation also provides the KDI and other research institutions with new opportunities to take advantage of scale economies because it has created a new policy research cluster by concentrating several institutions in a relatively small area. If Sejong manages to firmly establish itself as a center of policymaking, then those opportunities are more likely to outweigh any challenges in attracting quality researchers in the future.

\section{KDI LESSONS}

Is the KDI model relevant for other countries? The answer is no if we focus exclusively on environmental conditions. No two countries face the same conditions, and every country is clearly different than Korea in the 1960s or 1990s. We may conclude that the KDI model cannot be transplanted into another country if we pay attention only to conditions favorable to the development of the KDI such as leadership, a strong bureaucracy, and the support of aid agencies. But even in the presence of these conditions, the success of the KDI was not guaranteed or inevitable. For each favorable condition, we can cite an equally significant negative condition. Neither is it right to claim that the KDI represents a universal model; there is no one model right for everyone, every time.

Nevertheless, there seem to be several general lessons that can be gleaned from the case of the KDI. First is the importance of institutional and individual incentives. At the individual level, the KDI has been a leader in developing a financial and performance incentive system. At the institutional level, too, the KDI has often been rewarded with access to top policymakers, resources, key national research projects, and senior government positions for fellows and presidents.

The second lesson is the importance of organizational culture. Incentive systems would not have worked without the KDI's open and "liberal" organizational culture. This culture, in turn, is not an accident. From the first president on, KDI leaders have deliberately kept the organization small, horizontal and exclusive to nurture and support an open organizational culture. The KDI organizational culture has also been instrumental in maintaining the quality of KDI research by allowing the strict internal review of research papers and proposals. Like excellent private sector corporations, the KDI seems to have developed cultures that have incorporated the values and practices of pioneering leaders, which have survived for decades even after the passing of the original leaders (Peters and Watterman 1982).

Simultaneously, it is important to emphasize non-economic factors. As a center of excellence, the KDI has always been a place with strong institutional pride and autonomy. That is, non-financial recognition has been as important to KDI success as financial rewards. In retrospect, it is inconceivable how the KDI would have developed such a strong institutional identity without being recognized exclusively as a center of excellence by top leaders. 
Finally, it should be noted that the three success factors-strong incentives, organizational culture and the recognition as a center of excellence-are not independent; rather, they reinforce one another. Strong incentives are necessary to support a desired organizational culture and the position as the premier think tank. An open organizational culture helps maintain a system of incentives and control quality. Lastly, the recognition as a center of excellence produces a strong desire to continue to succeed, which requires the continuation of best practices such as incentives and open communication.

\section{REFERENCES}

Amsden, Alice H. 1990. Asia's Next Giant: South Korea and Late Industrialization. New York: Oxford University Press.

Amsden, Alice H. 1994. The Specter of Anglo-Saxonization is Haunting South Korea. In Kore's Political Economy: An Institutional Perspective, eds. LeeJay Cho and Yoon Hyung Kim. Boulder, CO: Westview Press.

Clark, Julia, and David Roodman. 2013. Measuring Think Tank Performance: An Index of Public Profile. CGD Policy Paper 025. Washington, DC: Center for Global Development.

Clifford, Mark L. 1998. Troubled Tiger: Businessmen, Bureaucrats, and Generals in South Korea, Armonk, NY: M. E. Sharpe.

Haggard, Stephen, and Jongryn Mo. 2000. The Political Economy of the Korean Financial Crisis. Review of International Political Economy 7(2): 197-218.

Han, Seunghee. 2014. Operation of the Economic Planning Board in the Era of High Economic Growth in Korea. Knowledge Sharing Program, KDI School of Public Policy and Management.

Kang, Myung-Koo. 2012. Mimetic Convergence: The Ascendance of Americantrained Economists in Financial Liberalization in Korea. Typescript, Department of Political Science, Baruch College.

McGann, James. 2014. 2013 Global Go To Think Tank Index Report. Think Tanks and Civil Societies Program, University of Pennsylvania.

Mo, Jongryn. 2001. The Case of Korea. In Guidance for Governance, eds. R. Kent Weaver and Paul Stares. Tokyo, Japan: Japan Center for International Exchange.

Moon, Chung-in, and Rashemi Prasad. 1994. Beyond the Developmental State: Networks, Politics, and Institutions. Governance, 7: 360-386.

Onis, Ziya. 1991. The Logic of the Developmental State. Comparative Politics, 24(1): 109-126.

Peters, Thomas J. and Robert Waterman. 1982. In Search of Excellence. NY: Warner Books.

Posen, Adam S. 2002. Think Tanks: Who's Hot and Who's Not. The International 
Economy, Fall: 8-59.

Prospect Magazine. 2012. Think Tank of the Year Awards 2012.

Ruble, Nicolas, S. 2000. Think Tanks: Who's Hot and Who's Not. The International Economy, Fall: 10-16.

Shinohara, Miyohei, Toru Yanagihara, and Kwang Suk Kim. 1983. The Japanese and Korean Experiences in Managing Development. World Bank Staff Working Papers 574. Washington, DC: World Bank.

Tirole, Jean. 1988. The Theory of Industrial Organization. Cambridge, MA: The MIT Press.

Trimbath, Susanne. 2005. Think Tanks: Who's Hot and Who's Not. The International Economy, Summer: 10-47.

Wade, Robert. 1990. Governing the Market. Princeton, NJ: Princeton University Press.

World Bank. 1983. World Development Report. 